ISSN: 1576-0162

DOI: http://dx.doi.org/10.33776/rem.v0i57.5182

\title{
DESINDUSTRIALIZACIŌN Y DESACELERACIÓN DE LA PRODUCTIVIDAD EN ESTADOS UNIDOS
}

\author{
DEINDUSTRIALISATION AND THE US \\ PRODUCTIVITY SLOWDOWN
}

Adrián Rial

arial@ucm.es

Universidad Complutense de Madrid

Recibido: febrero 2021; aceptado: julio 2021

\section{RESUMEN}

Tras el final de la Edad de Oro, la economía estadounidense ha sufrido una aceleración del proceso de desindustrialización que ha coincidido en el tiempo con una ralentización en el crecimiento de su productividad del trabajo. En este trabajo se analiza el vínculo existente entre ambos fenómenos conforme a un marco de causación acumulativa. Nuestros resultados muestran que la aceleraciōn del proceso de desindustrializaciōn se vincula con un incremento exógeno de la productividad en el sector manufacturero y con el impacto negativo sobre la producción manufacturera derivado del despegue de la penetraciōn importadora en el sector. De esta manera, la aceleraciōn del proceso de desindustrializaciōn habría contribuido a mitigar la ralentización en el crecimiento de la productividad agregada.

Palabras clave: desindustrialización, causación acumulativa, crecimiento de la productividad del trabajo, economía de Estados Unidos.

\section{ABSTRACT}

After the Golden Age, the US economy has suffered a speed-up in its deindustrialisation process and a productivity slowdown. This study examines the link between the two processes according to a cumulative causation framework. Our results show that the speed-up of deindustrialisation can be explained by an exogenous increase in labour productivity growth in the manufacturing sector and the negative impact on output growth in manufacturing that stems from the rise of import penetration. As a result, the speed-up of the deindustrialisation process has helped to countervail the slowdown in aggregate labour productivity growth.

Keywords: deindustrialisation, cumulative causation, labour productivity growth, US economy.

JEL Classification/Clasificación JEL: L16, L80, O47. 



\section{INTRODUCCIÓN}

Desde comienzos de la década de los setenta, la economía de EE.UU. ha experimentado una aceleración en su proceso de desindustrializaciōn ${ }^{1}$ (Gráfico 1). Aunque este retroceso relativo del sector manufacturero ha coincidido en el tiempo con la ralentización de la productividad del trabajo pos Edad de Oro (que ha pasado de crecer un 2,2\% en 1950-1969 a un 1,5\% en 1970-2018), la literatura apenas ha explorado el vínculo existente entre ambos fenómenos. Este desinterés por el papel desempeñado por la desindustrializaciōn se debe en buena medida a que en la literatura mainstream el crecimiento de la productividad no se ve afectado de manera endógena por los factores que conducen al cambio estructural, de manera que la desindustrializaciōn se entiende como un mero subproducto derivado del crecimiento económico. En contraposiciōn a esta visiōn relativamente estrecha del cambio estructural, la teoría kaldoriana y el enfoque SED (structural economic dynamics) han ofrecido visiones complementarias para explicar la interrelación existente entre el cambio estructural y el crecimiento económico.

Desde la teoría kaldoriana se enfatiza que el crecimiento económico depende de manera específica de la expansión del sector manufacturero (Kaldor, 1966, 1968, 1975). La manufactura sería, asî, motor de crecimiento debido a que esta presentaría una serie de características diferenciales con respecto al resto de sectores de la economía (Szirmai, 2012): un mayor crecimiento de la productividad, mayores posibilidades para aprovechar rendimientos crecientes a escala, una convergencia no condicional en el crecimiento de la productividad (Rodrik, 2013), unos encadenamientos más fuertes con el resto de industrias, una capacidad superior, dada su transabilidad, para financiar la importación de productos necesarios para el crecimiento y aliviar la restricción de la balanza de pagos, o una mayor acumulación de las capacidades necesarias para producir bienes más complejos (Hidalgo et al., 2007; Hidalgo y Hausmann, 2009). Entre todas estas características, el elemento nuclear

\footnotetext{
${ }^{1}$ En las economías avanzadas la expansión relativa del sector servicios sobre el empleo (terciarizaciōn) lleva aparejada habitualmente un proceso de desindustrializaciōn.

En este trabajo se adopta una perspectiva sectorial y se define el proceso de desindustrializaciōn como la pérdida de peso del sector manufacturero sobre el total del empleo (en horas trabajadas) de la economía.

Al adoptar un enfoque sectorial, se omite en el análisis cómo los vínculos productivos existentes entre el sector manufacturero y el sector servicios pueden difuminar las fronteras entre ambos sectores y matizar el concepto de desindustrializaciōn (véase, e.g., Berardino y Onesti, 2020a, 2020b).
} 


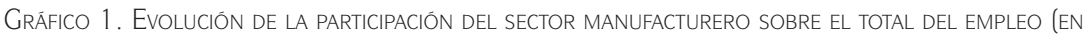
HORAS TRABAJADAS) DE LA ECONOMÍA

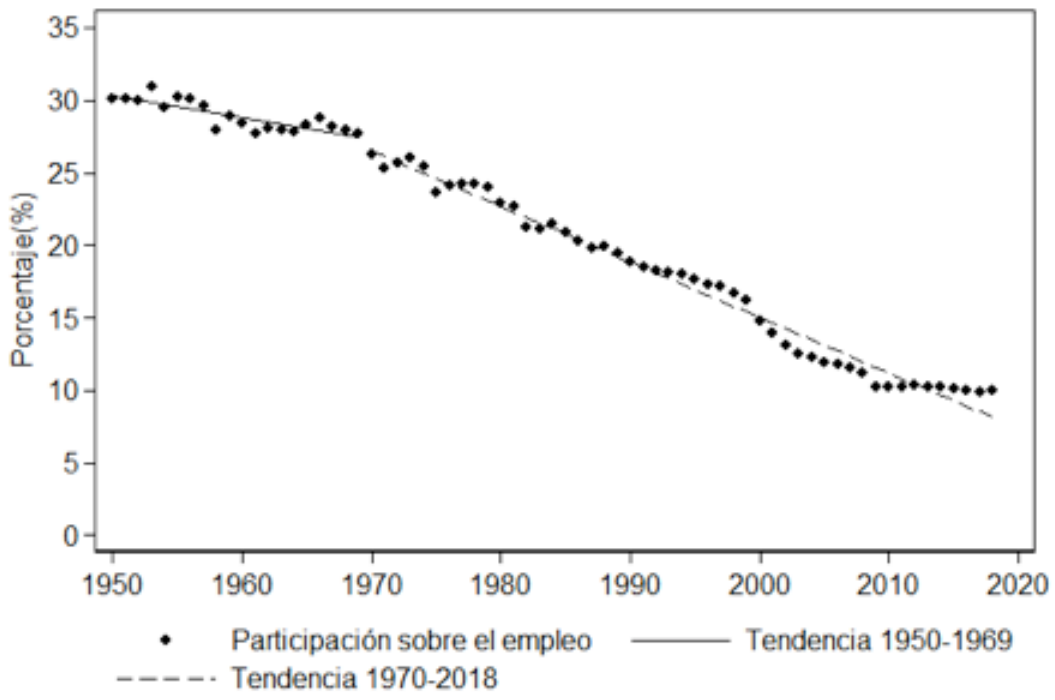

Fuente: elaboración propia a partir de BEA

en la teoría kaldoriana de crecimiento económico y cambio estructural es la existencia de rendimientos crecientes a escala, tal y como aparece recogida en la ley de Verdoorn. De acuerdo con esta ley, el crecimiento de la productividad en el sector manufacturero depende positivamente del ritmo de expansión de la demanda. Aunque la ley de Verdoorn constituye una suerte de caja negra (McCombie y Spreafico, 2016; Setterfield, 2019), la literatura kaldoriana relaciona los rendimientos crecientes a escala en la manufactura con los procesos dinámicos de learning by doing y de embodied technological change a los que daría lugar un mayor crecimiento de la demanda en este sector.

Partiendo de esta nociōn de rendimientos crecientes a escala, la teoría kaldoriana concibe el crecimiento como un proceso de causación acumulativa en el que tiene lugar una dinámica de retroalimentación entre la demanda y la productividad (Kaldor, 1970). Si bien, desde la relativa autonomía que le concede el principio keynesiano de demanda efectiva, el incremento de la demanda determina el crecimiento del output e impulsa el crecimiento de la productividad a través de los rendimientos crecientes, el incremento de la productividad afecta a su vez al crecimiento de la demanda a través de dos tipos de mecanismos: el mecanismo externo de causación acumulativa y el interno (Pini, 1996). El primero de estos mecanismos recoge cómo el incremento de la productividad impulsa la exportación a través de la mejora 
en la competitividad-precio de los bienes exportados (Dixon y Thirlwall, 1975; León-Ledesma, 2002; Targetti y Foti, 1997), mientras que el segundo refleja el impacto sobre los componentes de la demanda interna al que da lugar las ganancias de renta generadas por el crecimiento de la productividad (Boyer, 1988; Boyer y Petit, 1981 ; Castellaci y Álvarez, 2006). No obstante, el mecanismo externo de causación acumulativa ha sido puesto en duda en la literatura, afirmándose que la constancia a largo plazo de los precios relativos y la irrelevancia de la competitividad-precio ${ }^{2}$ frente a factores de competitividad no basados en el precio quiebran este mecanismo. Teniendo en cuenta estos argumentos y el tamaño del mercado interno en la economía estadounidense, en adelante solo consideraremos el mecanismo interno de causaciōn acumulativa.

Desde una perspectiva complementaria, el enfoque SED de Pasinetti (1981, 1993) considera de manera simultánea la oferta y la demanda en un modelo multisectorial, ilustrando cómo el cambio estructural y el crecimiento económico son el resultado de la transformación de los patrones de consumo y de la heterogeneidad del progreso técnico sectorial. Con todo, en la medida en que en el marco pasinettiano estos dos factores se consideran exógenos, el cambio estructural resulta ser un producto derivado del crecimiento económico, adoptando un rol pasivo con respecto a este. Para suplir estas carencias, Gualerzi $(2010,2012)$ propone un tratamiento más inclusivo del papel de la demanda. De acuerdo con este, el crecimiento económico se encuentra endógenamente determinado por las fuerzas que explican el cambio estructural, concretamente por el nexo existente entre el consumo y la inversión. Para Gualerzi, la transformación de los patrones de consumo resulta esencial para evitar la saturación de los mercados y el consiguiente estancamiento económico. Esta alteraciōn de los patrones de consumo depende del éxito que tengan la innovaciōn y la inversión autónoma en modular las preferencias de los consumidores, dando lugar a la creación de nuevos mercados o al aumento de la variedad de productos en los mercados existentes (Ciriaci et al., 2016; Falk y Hangsten, 2018; Vivarelli, 1995).

Si bien Gualerzi ofrece fundamentalmente argumentos de tipo verbal, Araujo y Trigg (2015) han formalizado un modelo multisectorial en el que combinan el enfoque SED con la noción de causación acumulativa. Como muestran en el modelo, la causación acumulativa no se restringe a operar dentro de los confines de la industria (con rendimientos crecientes a escala) que experimenta el shock de demanda. Dado que el shock de demanda estimula el crecimiento de la productividad en la industria y de la renta per cápita, esto dará lugar a un incremento de la demanda en el resto de industrias de la economía en función de cuál sea su elasticidad-renta de la demanda. En consecuencia, el shock inicial de demanda en una industria particular provocará un incremento de la productividad en otras industrias de la economía si estas

\footnotetext{
${ }^{2}$ No obstante, dentro del sector manufacturero existe una heterogeneidad sustancial en la elasticidadprecio de las diferentes industrias (Carlin et al., 2001).
} 
cuentan con rendimientos crecientes a escala. Este proceso refleja la idea de Fabricant (1942) de que las tasas de crecimiento de la productividad de las diferentes industrias resultan ser interdependientes (Metcalfe et al., 2006). Así, la causación acumulativa se manifiesta como un fenómeno macroeconómico (Araujo y Trigg, 2015; Young, 1928).

En síntesis, desde esta perspectiva que combina la teoría kaldoriana con el enfoque SED, se subraya que el crecimiento de la productividad agregada depende de que la demanda final se oriente hacia las industrias con rendimientos crecientes a escala, debido a la incapacidad de las industrias con rendimientos constantes para impulsar la renta per cápita a través del crecimiento de su demanda. De esta manera, si se identifica a las industrias manufactureras con aquellas industrias de la economía con rendimientos crecientes, un proceso de desindustrialización auspiciado, bien por una insuficiente expansiōn de la demanda en la manufactura, bien por una incapacidad del sector para responder con producciōn interna a ese incremento de la demanda, provocará una desaceleración de la causación acumulativa y de la productividad agregada. En este escenario, el proceso de desindustrialización se encontraría estrechamente vinculado con la desaceleración de la productividad.

Con todo, esta simplificación acerca de la interrelaciōn entre el proceso de desindustrialización y la desaceleraciōn de la productividad admite distintas críticas:

- Distintos estudios empíricos han mostrado que 1) existe una heterogeneidad sustancial en los rendimientos a escala en el seno de la manufactura (Magacho y McCombie, 2017; Romero y Britto, 2017; Romero y McCombie, 2016) y de los servicios (Di Meglio et al., 2018; Pieper, 2003) y 2) que la magnitud de los rendimientos a escala no es estable a lo largo del tiempo (Basu y Foley, 2013; Pieper, 2003; Romero y McCombie, 2016). En consecuencia, tanto el sector manufacturero como el sector no manufacturero pueden contribuir a la inestabilidad del diferencial en los rendimientos a escala.

- Esta inestabilidad emerge como un posible factor de desindustrialización. Como destaca una parte de la literatura de cambio estructural (AlvarezCuadrado et al., 2017; Baumol, 1967; Ngai y Pissarides, 2007), la transformación de la estructura productiva puede encontrarse vinculada con las diferencias existentes en las condiciones tecnológicas entre sectores. Así, el proceso de desindustrialización podría verse auspiciado por una evolución favorable del diferencial en los rendimientos a escala del sector manufacturero, de modo que una ampliaciōn del diferencial por un incremento de los rendimientos a escala en la manufactura aceleraría la productividad en el conjunto de la economía.

- Dado el avance progresivo del sector no manufacturero (más específicamente, del sector servicios) sobre el total del empleo y del producto nominal, la causación acumulativa en el conjunto de la economía se encuentra crecientemente determinada por la capacidad de este sector de impulsar la renta per cápita mediante sus ganancias de productividad. Como hemos visto, en un escenario de rendimientos crecientes, un shock positivo 
(negativo) de demanda concentrado en el sector no manufacturero impulsaría (constreñiría) tambiēn la producciōn y la productividad en la manufactura. En estas circunstancias, las magnitudes del diferencial en los rendimientos a escala y del diferencial en las elasticidades de demanda resultan fundamentales para definir el vínculo entre el crecimiento de la productividad agregada y el proceso de desindustrializaciōn. Asī, ante un diferencial en los rendimientos a escala pequeño y unas elasticidades de demanda similares entre los dos sectores, un shock positivo (negativo) de demanda en el sector no manufacturero aceleraría (desaceleraría) de manera similar el crecimiento tanto de la productividad como de la producción en ambos sectores. En consecuencia, tendría lugar una aceleraciōn (desaceleraciōn) de la productividad agregada que no se encontraría vinculada con un proceso de cambio estructural.

Partiendo de este marco de causación acumulativa, en lo que resta de trabajo nuestro objetivo es analizar la interrelación entre la aceleración del proceso de desindustrialización y la ralentización en el crecimiento de la productividad del trabajo sufridas por Estados Unidos en 1970-2018, tras el final de la Edad de Oro.

La estructura del trabajo consiste en tres epígrafes que siguen a esta introducciōn. En el epígrafe 2 se abordan las consideraciones metodológicas, exponiendo el modelo con el que vamos a estudiar la interrelación entre el proceso de desindustrialización y el crecimiento de la productividad. En el epígrafe 3 se discuten los resultados derivados de la estimación del modelo. Finalmente, el epigrafe 4 recoge las principales conclusiones obtenidas en este estudio.

\section{Consideraciones metodolóGicas}

En términos descriptivos, como evidencia el Gráfico 2, la aceleraciōn del proceso de desindustrialización se encuentra vinculada con el hecho de que la manufactura ha visto cómo se incrementaba con fuerza su diferencial en el crecimiento de la productividad y de manera más moderada su diferencial en el crecimiento del output. Por su parte, la desaceleraciōn de la productividad agregada se explicaría por el carăcter estacionario sobrevenido del sector no manufacturero, que ha sufrido una ralentización aguda en el incremento de su productividad.

Teniendo en cuenta estos hechos, nuestro objetivo es formular un modelo que nos permita aporta una explicación causal, desde un marco de causación acumulativa, sobre los factores que determinan la evoluciōn de dichos diferenciales y del crecimiento de la productividad agregada. De esta manera, proponemos un modelo de ocho ecuaciones con el que tratamos de recoger cómo opera el mecanismo interno de causación acumulativa para cada uno de los dos sectores en los que dividimos la economía: el sector manufacturero y el sector no manufacturero. 
GRÁFICO 2. CRECIMIENTO PROMEDIO ANUAL DEL OUTPUT, DE LA PRODUCTIVIDAD DEL TRABAJO Y DEL EMPLEO POR SECTORES

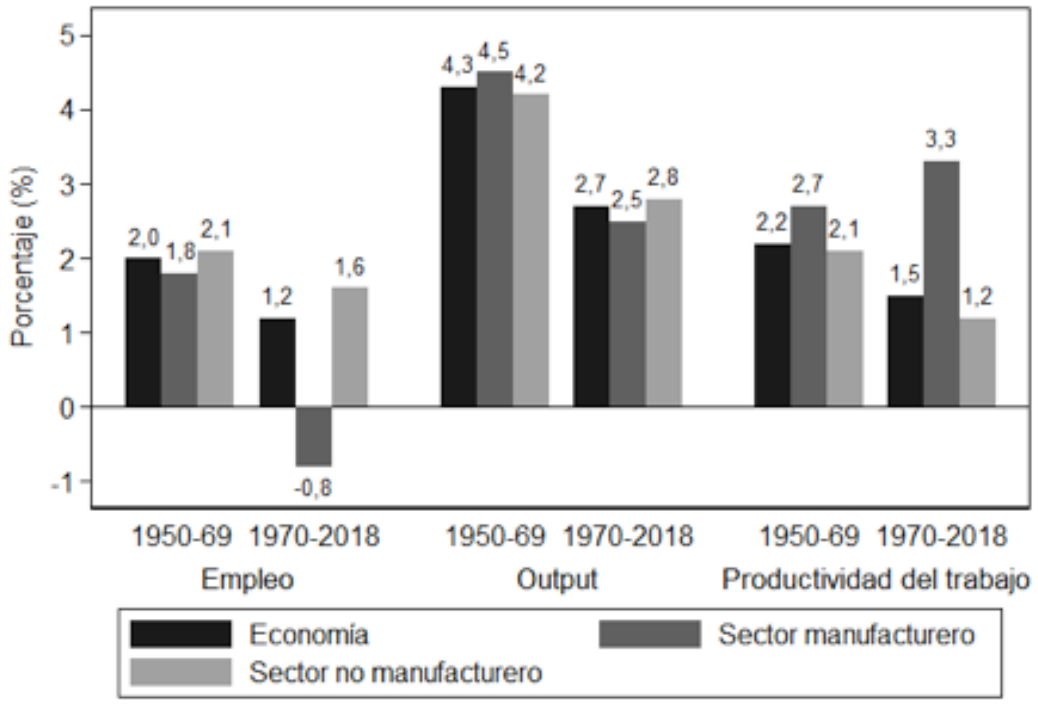

Fuente: elaboración propia a partir de BEA

Las ecuaciones relativas al sector manufacturero son las siguientes:

$c_{M_{t}}=\beta_{0}+\beta_{1}(w-h)_{t}+\beta_{2}(b-h)_{t}+\beta_{3} h_{t}+\beta_{4}\left(p_{M}-p_{N M}\right)_{t}+\beta_{5} I N N O_{M_{t}}+\beta_{6}\left(\frac{D_{H}}{P I B}\right)_{t}+\beta_{7} d_{H_{t}}+\varepsilon_{1_{t}}(1)$

$i_{E Q_{t}}=\beta_{8}+\beta_{9} y_{t}+\beta_{10}\left(\frac{B}{Y}\right)_{t}+\varepsilon_{2_{t}}(2)$

$y_{M_{t}}=\beta_{11}+\beta_{12} C_{M_{t}}+\beta_{13} i_{E O_{i}}+\beta_{14}\left(\frac{M_{M}}{Y_{M}}\right)_{t}+\boldsymbol{\varepsilon}_{3_{t}}(3)$

$q_{M_{t}}=\beta_{15}+\beta_{16} y_{M_{i t}}+\beta_{17}\left(k_{M}-y_{M}\right)_{i t}+\beta_{18} I N N O_{M_{t i}}+\varepsilon_{4 t}(4)$

La ecuaciōn (1) recoge la funciōn de consumo final de manufacturas. De acuerdo con esta, el crecimiento del consumo final de manufacturas $\left(C_{M}\right)$ depende de los incrementos del salario por hora $(w-h)$ y del beneficio por hora $(b-h)$, del crecimiento del empleo agregado en horas ( $h$ ), de la evolución del precio relativo de la manufactura $\left(P_{M}-P_{N M}\right)$, del esfuerzo innovador del sector manufacturero $\left(I N N O_{M}\right.$ ) (ratio de la inversiōn en I+D sobre el valor añadido del sector), de la ratio de la deuda de los hogares sobre el PIB $\left(\frac{D H}{P I B}\right)$ y del incremento real de la deuda de los hogares. 
En lugar de estimar la elasticidad-renta, se ha preferido diferenciar, por un lado, el papel del incremento de los componentes del ingreso por hora y, por otro, el rol de la creación de empleo. Si bien la creación de empleo puede suponer un estímulo importante para el consumo, el mecanismo interno de causaciōn acumulativa operaría fundamentalmente a través del incremento de los componentes del ingreso por hora y de la reducción del precio relativo. En lugar de utilizar como variable explicativa el crecimiento del ingreso por hora, diferenciamos el papel de sus dos componentes: el incremento del salario por hora y el del beneficio por hora. De esta manera, siguiendo a la literatura kaleckiana (e.g. Baccaro y Pontusson, 2016; Naastepad y Storm, 2006), buscamos comprobar si la elasticidad del consumo con respecto al salario por hora supera a la del beneficio por hora. De ser asî, el cambio que se ha producido desde los años setenta en la participación de los salarios sobre la renta, que ha pasado de seguir una tendencia ascendente en 19501969 a sufrir una descendente en 1970-2018 (Gráfico 3), habría impactado de manera negativa sobre el consumo final.

Asimismo, en la ecuaciōn de consumo incorporamos el esfuerzo innovador del sector manufacturero, que actúa como proxy de la introducciōn de nuevos productos al mercado, tratando de captar su importancia a la hora de contrarrestar la saturación de los mercados.

GRÁFICO 3. EVOLUCIŌN DE LA PARTICIPACIŌN DE LOS SALARIOS SOBRE LA RENTA

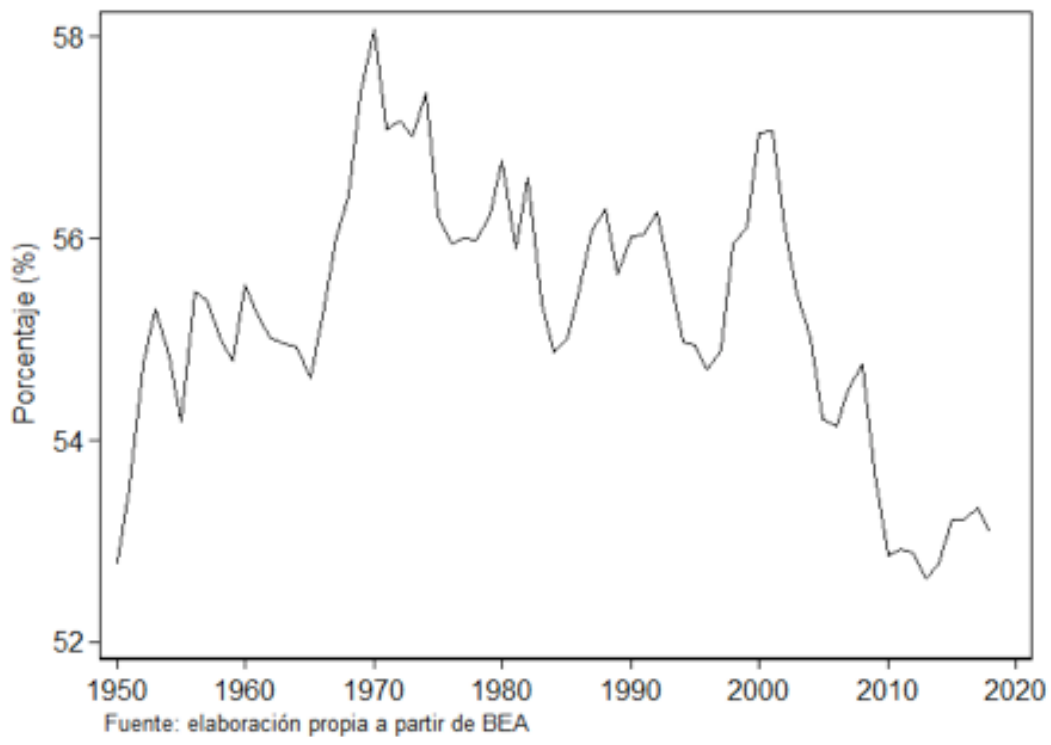


Junto con estas variables, consideramos tambiēn el efecto que ha podido desplegar sobre el consumo el endeudamiento de los hogares. Este actuaría sobre el consumo a travês de dos vías contradictorias (Stockhammer y Wildauer, 2016). Por un lado, el incremento real de la deuda de los hogares impulsaría la renta disponible de los hogares y su capacidad para financiar su demanda de consumo. Por otro lado, el aumento de la ratio de la deuda de los hogares sobre el PIB incrementaría la carga financiera de los hogares, constriñendo la renta disponible de los hogares y, en consecuencia, el consumo. De esta manera, el aumento sostenido de la ratio de la deuda de los hogares sobre el PIB que ha venido experimentando la economía estadounidense (Grăfico 4) ha podido constreñir de manera notable el incremento del consumo.

Más allá del consumo final de productos manufactureros, incorporamos también una ecuaciōn para el crecimiento de la demanda de inversiōn en bienes de equipo (ecuaciōn (2)). Dado que esta variable se considera determinante del crecimiento del output manufacturero en la ecuación (3), modelizamos su comportamiento con el fin de considerar otra vía a través de la cual opera la causaciōn acumulativa. De acuerdo con la ecuaciōn (2), el crecimiento de la inversión en bienes de equipo depende del incremento del PIB, reflejando el efecto acelerador, y de la cuota de beneficios sobre el producto $\left(\frac{B}{Y}\right)$, que actúa como proxy del efecto rentabilidad.

Gráfico 4. Evolución de la ratio de la deuda de los hogares sobre el PIB

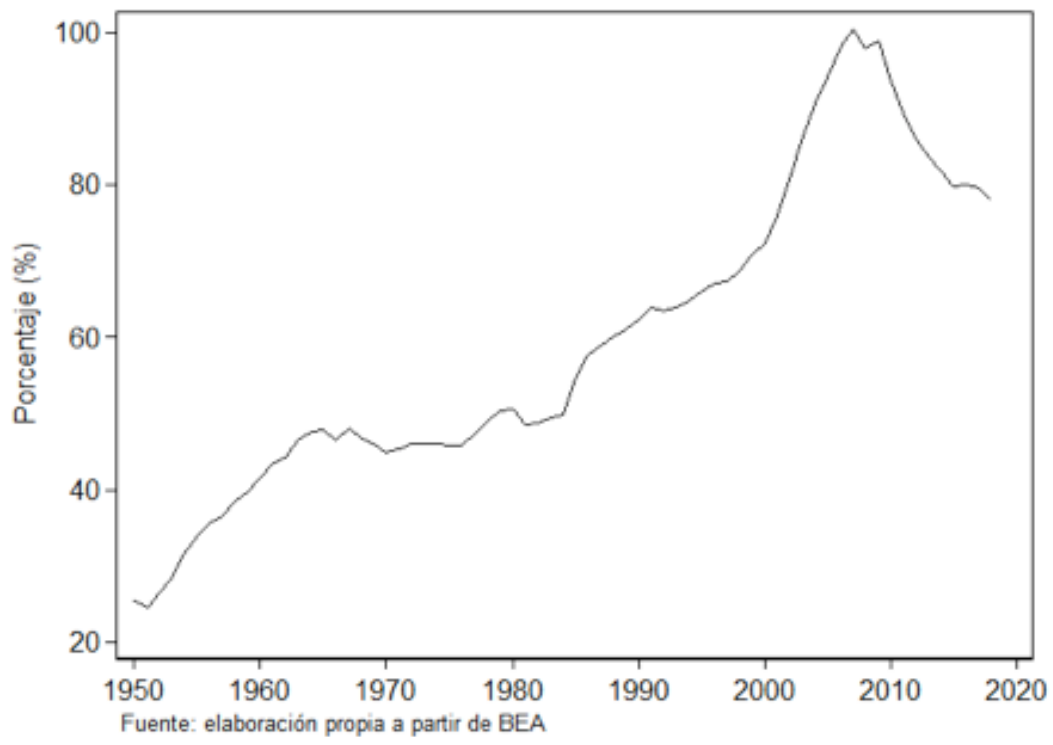


La ecuación (3) recoge cómo el crecimiento del valor añadido en la manufactura depende del incremento del consumo final de manufacturas, del crecimiento de la inversiōn en bienes de equipo $\left(I_{E Q}\right)$ y de la penetraciōn importadora en el sector. Junto con el estímulo que supone el incremento del consumo, la producción manufacturera también se vería positivamente afectada por un aumento de la demanda de inversión de bienes de equipo en el conjunto de la economía. Por el contrario, esperamos que la penetración importadora se encuentre negativamente relacionada con el aumento de la producción en la manufactura.

La ecuación (4) se corresponde con una ley de Verdoorn ampliada para el sector manufacturero. De acuerdo con esta, el crecimiento de la productividad (por hora trabajada) en la manufactura $\left(q_{M}\right)$ depende del crecimiento de la producción manufacturera, del incremento del coeficiente capital-producto $\left(K_{M}-Y_{M}\right)$ y del esfuerzo innovador en el sector $\left(\frac{M_{M}}{Y_{M}}\right)$.

El sector manufacturero presentará rendimientos crecientes si el coeficiente de Verdoorn $\left(\beta_{16}\right)$ es mayor que 0 , mientras que exhibirá rendimientos constantes si este coeficiente no es significativamente distinto de 0 . Dado que el coeficiente capital-producto no se mantiene constante a lo largo del tiempo, en la ecuación se incorpora esta variable explicativa porque su omisión conduciría a la obtención de un coeficiente de Verdoorn sesgado (McCombie, 1982).

Asimismo, en esta ecuación utilizamos el esfuerzo innovador como variable de control adicional, aunque esperamos que el impacto directo de esta variable sobre el crecimiento de la productividad sea limitado (León-Ledesma, 2002), canalizándose fundamentalmente a través del propio coeficiente de Verdoorn (Romero y Britto, 2017).

Finalmente, es necesario aclarar en este punto que, a diferencia del resto de ecuaciones, la unidad de análisis en la ecuaciōn de productividad no es el agregado del sector, sino las industrias que componen el sector (denotadas por el subíndice i en la ecuación). La razón de este cambio en la unidad de análisis es que la estimación de la ley de Verdoorn a través de series temporales da lugar a la obtención de rendimientos constantes a escala, no porque estos existan en términos empíricos, sino porque dicha estimación captura la identidad contable de la función de producción (McCombie y Spreafico, 2016). Para corregir este problema, la ley de Verdoorn se estima para el pool de industrias del sector.

Por su parte, las ecuaciones correspondientes al sector no manufacturero son similares a las de la manufactura, con solo dos diferencias: 1) donde antes se introducían variables relativas la manufactura, ahora se incorporan variables referentes al sector no manufacturero (subíndice NM) y 2) el crecimiento del output del sector no manufacturero se encuentra determinado por el crecimiento de su consumo final y por el incremento de la demanda de inversión residencial y en estructuras, de manera que la ecuación relativa a la demanda de inversión en bienes de equipo es reemplazada por una ecuación relativa a 
la inversiōn residencial y en estructuras (con idénticos determinantes). Asī, las ecuaciones correspondientes al sector no manufacturero serían las siguientes:

$$
\begin{aligned}
& c_{N M_{i}}=\beta_{19}+\beta_{20}(w-h)_{t}+\beta_{21}(b-h)_{t}+\beta_{22} h_{t}+\beta_{23}\left(p_{M}-P_{N M}\right)_{t}+\beta_{24} I N N O_{N M_{t}}+\beta_{25}\left(\frac{D_{H}}{P I B}\right)_{t}+\beta_{26} d_{H_{i}}+\varepsilon_{5_{t}}(5) \\
& i_{\text {RESESTR }}=\beta_{27}+\beta_{28} y_{t}+\beta_{29}\left(\frac{B}{Y}\right)_{t}+\varepsilon_{\sigma_{\mathrm{t}}}(6) \\
& y_{N M_{\tau}}=\beta_{30}+\beta_{31} C_{N M_{\tau}}+\beta_{32} i_{\text {RESESTR }}+\varepsilon_{7_{t}}(7) \\
& q_{N M_{i}}=\beta_{33}+\beta_{34} y_{N M_{i t}}+\beta_{35}\left(k_{N M}-y_{N M}\right)_{i t}+\beta_{36} I N N O_{N M_{T}}+\varepsilon_{8_{i t}}(8)
\end{aligned}
$$

Con el objetivo de facilitar la comprensión del modelo, se recogen en el Cuadro 1 de manera sintética las variables empleadas en las distintas ecuaciones para caracterizar la causación acumulativa en cada uno de los sectores.

Este modelo de ocho ecuaciones es estimado para el periodo 1950-2018. Dado que la aceleraciōn del proceso de desindustrialización y la ralentizaciōn en el crecimiento de la productividad que tienen lugar en 1970-20183 ocurren con respecto al periodo relativo a la Edad de Oro (1950-1969), es necesario

\begin{tabular}{|c|c|c|c|}
\hline \multicolumn{2}{|l|}{ Sector manufacturero } & \multicolumn{2}{|l|}{ Sector no manufacturero } \\
\hline Variables dependientes & Variables explicativas & Variables dependientes & Variables explicativas \\
\hline $\begin{array}{l}\text { Consumo final de manu- } \\
\text { facturas: ecuaciôn (1) }\end{array}$ & $\begin{array}{l}\text { salario por hora, beneficio } \\
\text { por hora, horas, precios } \\
\text { relativos, esfuerzo innova- } \\
\text { dor en el sector, deuda de } \\
\text { los hogares sobre el PIB, } \\
\text { deuda de los hogares }\end{array}$ & $\begin{array}{l}\text { Consumo final de produc- } \\
\text { tos no manufactureros: } \\
\text { ecuación (5) }\end{array}$ & $\begin{array}{l}\text { salario por hora, beneficio } \\
\text { por hora, horas, precios } \\
\text { relativos, esfuerzo innova- } \\
\text { dor en el sector, deuda de } \\
\text { los hogares sobre el PIB, } \\
\text { deuda de los hogares }\end{array}$ \\
\hline $\begin{array}{l}\text { Inversiôn en bienes de } \\
\text { equipo: ecuaciōn (2) }\end{array}$ & PIB, cuota de beneficios & $\begin{array}{l}\text { Inversiōn residencial y en } \\
\text { estructuras: ecuaciôn (6) }\end{array}$ & PIB, cuota de beneficios \\
\hline $\begin{array}{l}\text { Valor añadido en la manu- } \\
\text { factura: ecuaciōn (3) }\end{array}$ & $\begin{array}{l}\text { Consumo final de } \\
\text { manufacturas, inversiôn } \\
\text { en bienes de equipo, } \\
\text { penetraciôn importadora } \\
\text { en el sector }\end{array}$ & $\begin{array}{l}\text { Valor añadido no manufac- } \\
\text { turero: ecuaciôn (7) }\end{array}$ & $\begin{array}{l}\text { Consumo final de produc- } \\
\text { tos no manufactureros, } \\
\text { inversiôn residencial y en } \\
\text { estructuras }\end{array}$ \\
\hline $\begin{array}{l}\text { Productividad manufactu- } \\
\text { rera: ecuación ( } 4 \text { ) }\end{array}$ & $\begin{array}{l}\text { Valor añadido en la } \\
\text { manufactura, coeficiente } \\
\text { capital-producto en el } \\
\text { sector, esfuerzo innovador } \\
\text { en el sector }\end{array}$ & $\begin{array}{l}\text { Productividad no manufac- } \\
\text { turera: ecuación (8) }\end{array}$ & $\begin{array}{l}\text { Valor añadido no ma- } \\
\text { nufacturero, coeficiente } \\
\text { capital-producto en el } \\
\text { sector, esfuerzo innovador } \\
\text { en el sector }\end{array}$ \\
\hline
\end{tabular}
incorporar también este último periodo para investigar qué factores han auspiciado estos dos fenómenos. Con el fin de detectar si se han producido

CuAdro 1. Síntesis de LAS VARIABLES UTILIZADAS EN EL MODELO PARA CADA UNO DE LOS DOS SECTORES

Fuente: elaboraciōn propia.

${ }^{3}$ Aunque serīa posible discernir diferentes subperiodos entre 1970 y 2018 (e.g. el subperiodo relativo a 1996-2004, en el que tiene lugar una aceleraciōn tanto del proceso de desindustrializaciōn como de la productividad, o el correspondiente a 2005-2018, en el que la ralentizaciōn de la desindustrializaciôn coincide en el tiempo con la desaceleraciōn de la productividad), se ha optado por tomar el periodo 1970-2018 en su conjunto para no volver excesivamente complejo el análisis. 
cambios significativos en los coeficientes de las variables entre estos dos periodos, utilizamos dummies multiplicativas (junto con dummies para las constantes) (Castellaci y Álvarez, 2006). Si bien inicialmente introdujimos dummies para todas las variables, en la especificaciōn final únicamente se conservan aquellas que son significativas. Cuando la dummy resulta ser significativa y es reportada en nuestros resultados, el coeficiente relativo a 1970-2018 es igual a la suma del coeficiente base (el de 1950-1969) y el de la dummy. En caso de que la dummy no sea significativa, el coeficiente del segundo periodo coincide con el del primer periodo. Junto con la utilización de dummies, prestamos especial atención al cambio en las contribuciones de los diferentes factores en los dos periodos. Estas contribuciones se calculan como el producto del coeficiente estimado por el valor promedio de la variable durante el periodo correspondiente. De esta manera, el cambio en las contribuciones puede deberse tanto a un cambio en el valor promedio de la variable como a una variación en los coeficientes.

Para todas las ecuaciones se utilizan datos de frecuencia anual, excepto para las ecuaciones de productividad. En estas se emplean medias móviles no superpuestas de cinco años con el fin de evitar capturar la relación de corto plazo existente entre el crecimiento del output y el incremento de la productividad (ley de Okun) (Di Meglio et al., 2018; Magacho y McCombie, 2017; Pieper, 2003).

Las variables utilizadas se encuentran expresadas en términos reales, salvo aquellas relativas a ratios, que se calculan a partir de variables en términos nominales. El deflactor empleado es el del PIB, excepto para los incrementos del salario y del beneficio, que se deflactan con el IPC. Asimismo, la variaciōn del precio relativo se calcula sobre la base de la evolución de los precios de consumo.

Con respecto al método de estimaciōn empleado, en lugar de estimar el sistema de ecuaciones de manera simultánea, adoptamos una aproximaciōn más modesta y estimamos cada ecuaciōn de manera individual corrigiendo los problemas específicos de heterocedasticidad, autocorrelaciōn o endogeneidad cuando estos están presentes. De esta manera, en aquellas ecuaciones en las que hallamos que alguna de las variables explicativas resulta ser endógena, aplicaremos el estimador LIML (limited-information maximum likelihood) (en caso de errores independientes e idénticamente distribuidos (i.i.d.)) o CUE (continuous updating estimator) (cuando existen errores no i.i.d.), que presentan mejores propiedades que el estimador 2SLS (two-stage least squares) en muestras pequeñas y son más robustos ante la existencia de instrumentos débiles. Por su parte, si no detectamos problemas de endogeneidad pero sí de autocorrelaciōn, aplicamos el método Cochrane-Orcutt en aquellas ecuaciones en las que la unidad de análisis es el sector y el método poo/ mínimos cuadrados ordinarios con errores clusterizados por industrias para las ecuaciones de productividad. Finalmente, en caso de ausencia de problemas de endogeneidad y autocorrelación, se utiliza el método de mínimos cuadrados ordinarios, 
empleando errores robustos ante la presencia de heterocedasticidad cuando es necesario.

La fuente principal de datos empleada en este trabajo es el Bureau of Economic Analysis (BEA), de la que se toman los datos relativos a todas las variables, con la única excepción de la deuda de los hogares (que se toma de la Global Debt Database del FMI) y las variables utilizadas en las ecuaciones de productividad. Debido al cambio en el sistema de clasificación estadounidense del SIC al NAICS, el BEA no cuenta con una desagregación consistente del sector manufacturero y del no manufacturero desde 1950 que nos permita estimar la ley de Verdoorn para cada uno de estos sectores. Para corregir este problema, hacemos uso de los datos de WORLD KLEMS (actualizaciōn de abril de 2013) (Jorgenson et al., 2012), en la que se recogen diferentes variables relativas al crecimiento de 32 industrias $(13$ manufactureras y 19 no manufactureras) para el periodo 1947-2010. Con todo, dado que WORLD KLEMS no proporciona datos relativos a inversión en I+D, tomamos estos datos del BEA para construir la variable del esfuerzo innovador que se emplea en las ecuaciones de productividad.

\section{Resultados}

La Tabla 1 recoge los resultados de la estimación de nuestro modelo de ocho ecuaciones. Con el fin de elaborar una explicación acerca de la interrelaciōn existente entre la aceleraciōn del proceso de desindustrializaciōn y la ralentización en el crecimiento de la productividad agregada, primero compararemos cada par de ecuaciones homólogas de los dos sectores y posteriormente elaboraremos una interpretaciōn global a partir de los resultados obtenidos en el conjunto de ecuaciones.

En lo que respecta al consumo final (ecuaciones (1) y (5)), en ambos sectores son significativas al 5\% el crecimiento del salario-hora, el incremento de las horas trabajadas, el esfuerzo innovador respectivo de cada sector y el crecimiento de la deuda de los hogares. La variación de los precios relativos solo es significativa al 10\% para ambos sectores y presenta coeficientes reducidos, lo cual puede deberse a que la agregaciōn sectorial reduce la importancia del mecanismo de los precios relativos en beneficio del papel del incremento de la renta y de sus componentes. Asimismo, el crecimiento del beneficio-hora solo es significativo para el consumo final de productos manufactureros, mientras que la ratio de la deuda de los hogares sobre el PIB solo lo es para el sector no manufacturero.

Dado que el sector manufacturero presenta elasticidades relativas al salario-hora, al beneficio-hora y a las horas trabajadas superiores a las del sector no manufacturero, la desaceleración de estas tres variables en 19702018 despliega un impacto sustancialmente más negativo sobre el consumo final del sector manufacturero (-1,9 puntos) que sobre el del sector no manufacturero $(-0,8$ puntos). Con todo, la ralentización del consumo final en 


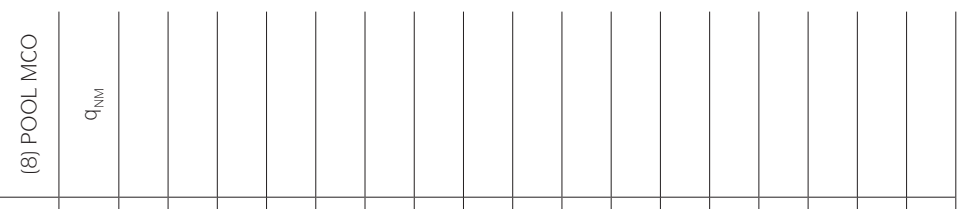

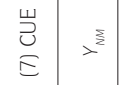

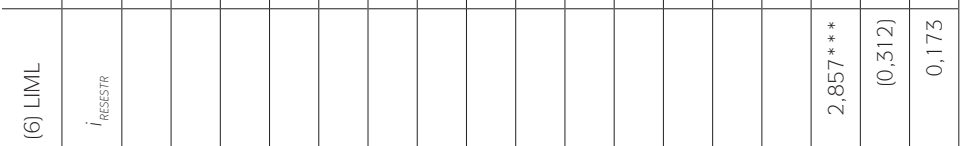

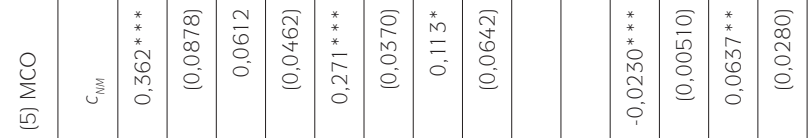

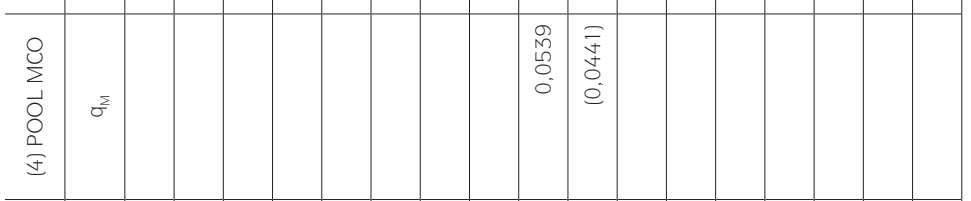

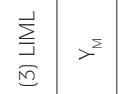

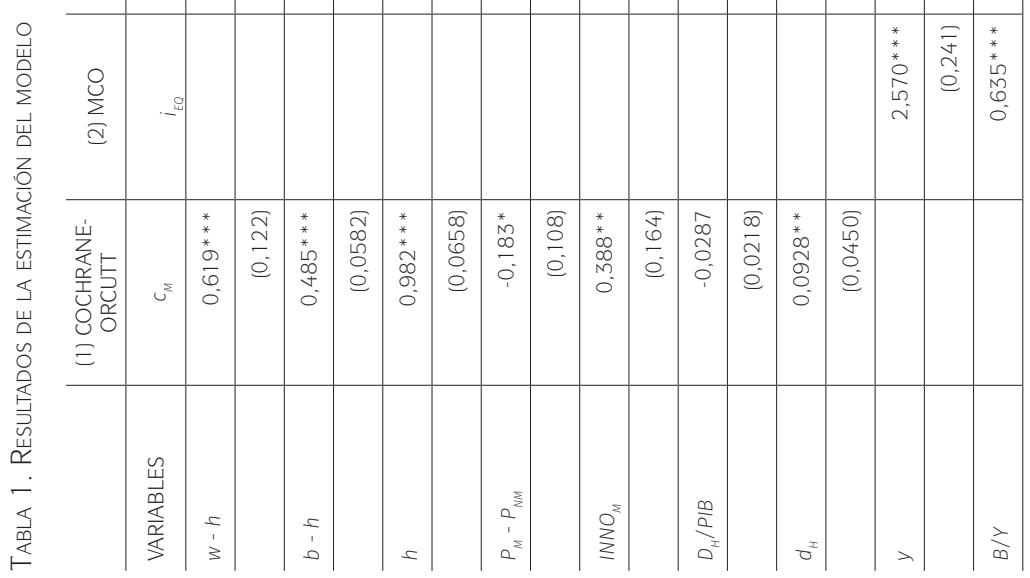




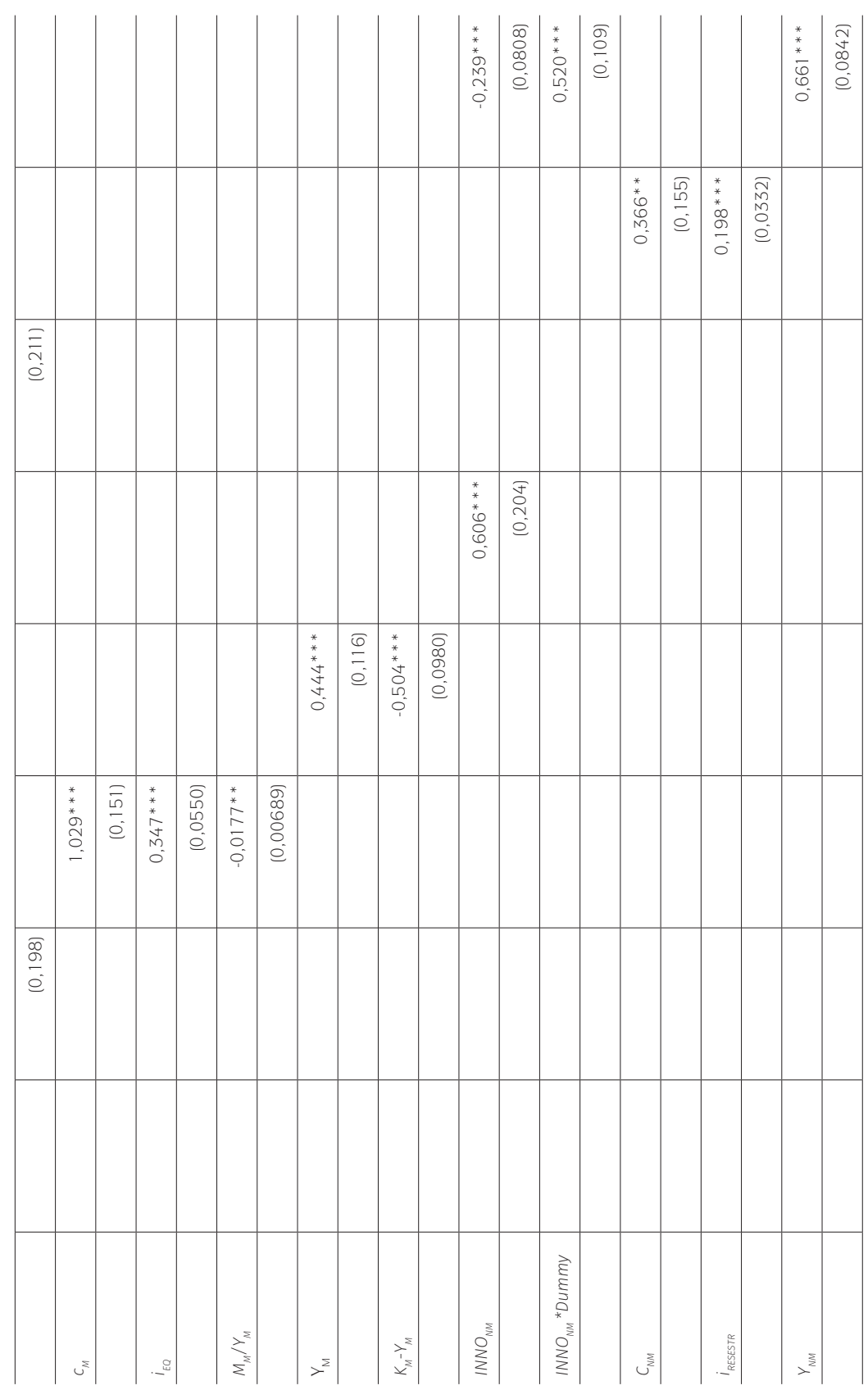




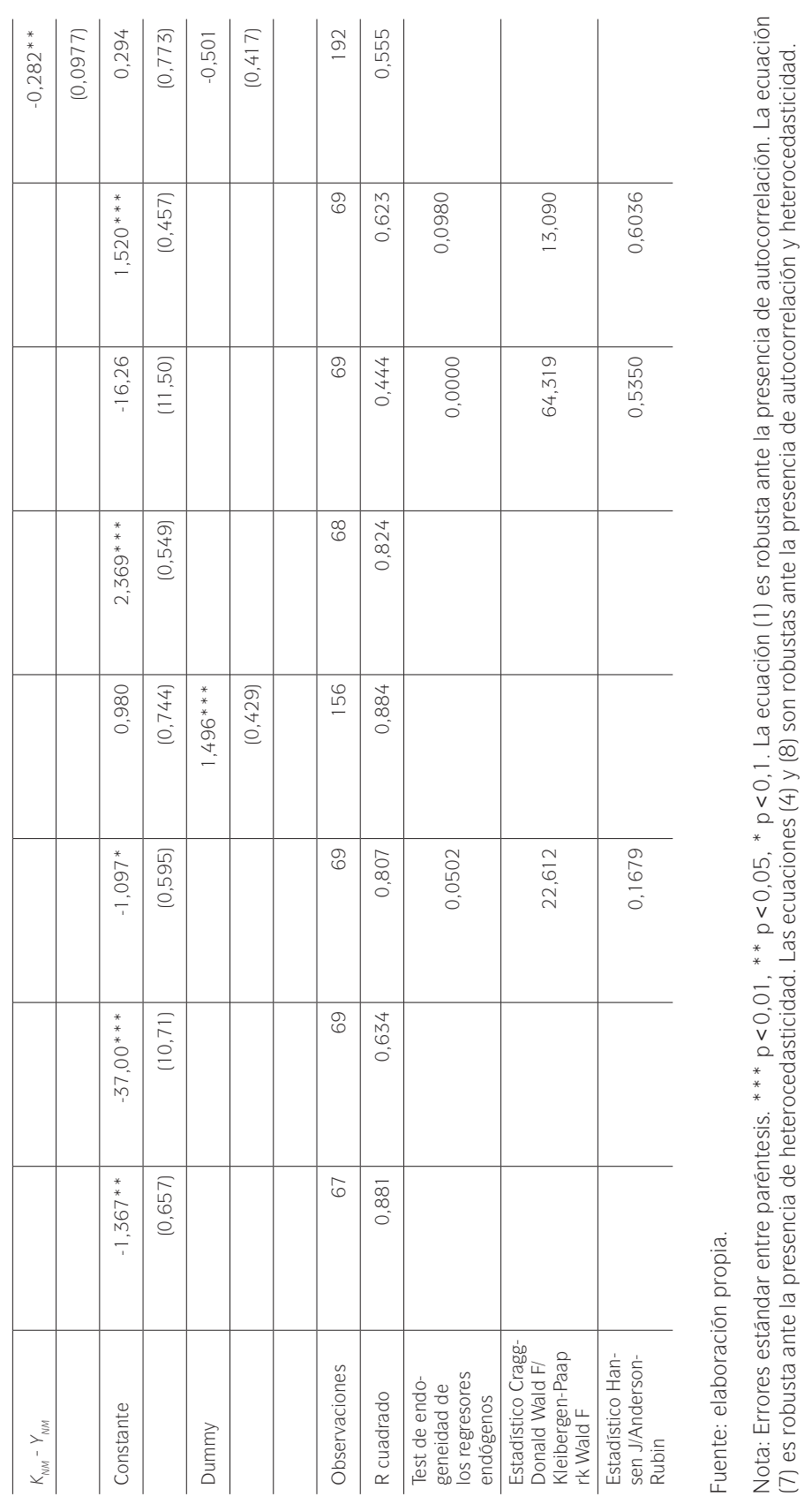


el sector manufacturero en el segundo periodo ha sido moderada debido al efecto contrarrestante desplegado por el auge del esfuerzo innovador, que contribuye en 1,8 puntos, mientras que el sector no manufacturero ha sufrido una desaceleraciōn más severa por el impacto derivado del incremento de la ratio de la deuda de los hogares sobre el PIB (-0,6 puntos). Junto con estos factores, el cambio que ha tenido lugar en la distribuciōn del ingreso en 1970-2018 con respecto a 1950-1969 también ayuda a explicar que el sector no manufacturero haya experimentado una desaceleraciōn más fuerte en su consumo final. En la medida en que el coeficiente relativo al salario por hora es significativamente superior al del beneficio por hora en el sector no manufacturero, el cambio que tiene lugar desde una distribución del ingreso favorable a los salarios en 1950-1969 a una distribución del ingreso favorable a los beneficios en 1970-2018 contribuye a desacelerar el consumo final en $-0,3$ puntos. Por el contrario, dado que para el sector manufacturero encontramos que el coeficiente del salario-hora no es significativamente distinto al del beneficio-hora, los cambios en la distribuciōn del ingreso no afectan al crecimiento del consumo final de productos manufactureros.

En consecuencia, la evolución diferencial en el consumo final de bienes manufactureros y de productos no manufactureros se explica, en parte, por el papel de la innovación. A pesar de que el esfuerzo innovador presenta un coeficiente similar en ambos sectores, el estancamiento de esta variable en el sector no manufacturero4 (Gráfico 5) no permite compensar el impacto negativo que se deriva de la desaceleraciōn en los componentes de la renta, del aumento en la ratio de la deuda de los hogares sobre el PIB y de una distribuciōn del ingreso más favorable a los beneficios.

Por lo que respecta a la demanda de inversión (ecuaciones (2) y (6)), tanto la inversión en bienes de equipo como la inversión residencial y en estructuras presentan un efecto acelerador significativo y de magnitud asimilable. El efecto rentabilidad, en cambio, solo es significativo para la inversión en bienes de equipo. Así, la ralentización del crecimiento de la producción agregada contribuye de manera negativa tanto al incremento de la inversión en bienes de equipo (-4 puntos) como al de la inversión residencial y en estructuras $(-4,6$ puntos), mientras que el incremento de la cuota de beneficios contribuye de manera positiva (2,6 puntos) únicamente en la ecuación en la que el efecto rentabilidad es significativo. En consecuencia, de acuerdo con nuestro modelo, el diferencial en el crecimiento de ambas inversiones se explicaría por el impacto desplegado por el aumento de la cuota de beneficios sobre la inversión en bienes de equipo, lo cual permite contrarrestar en parte la contribuciōn negativa que se deriva de la ralentizaciōn de la producciōn.

En lo que respecta a la producciōn sectorial (ecuaciones (3) y (7)), las distintas variables explicativas consideradas en cada ecuaciōn son

\footnotetext{
${ }^{4}$ No obstante, ha de tenerse en cuenta que, ante los problemas existentes en la definición del output de los servicios, la innovaciōn en el sector servicios puede encontrarse notablemente infraestimada (Gallouj y Savona, 2009).
} 


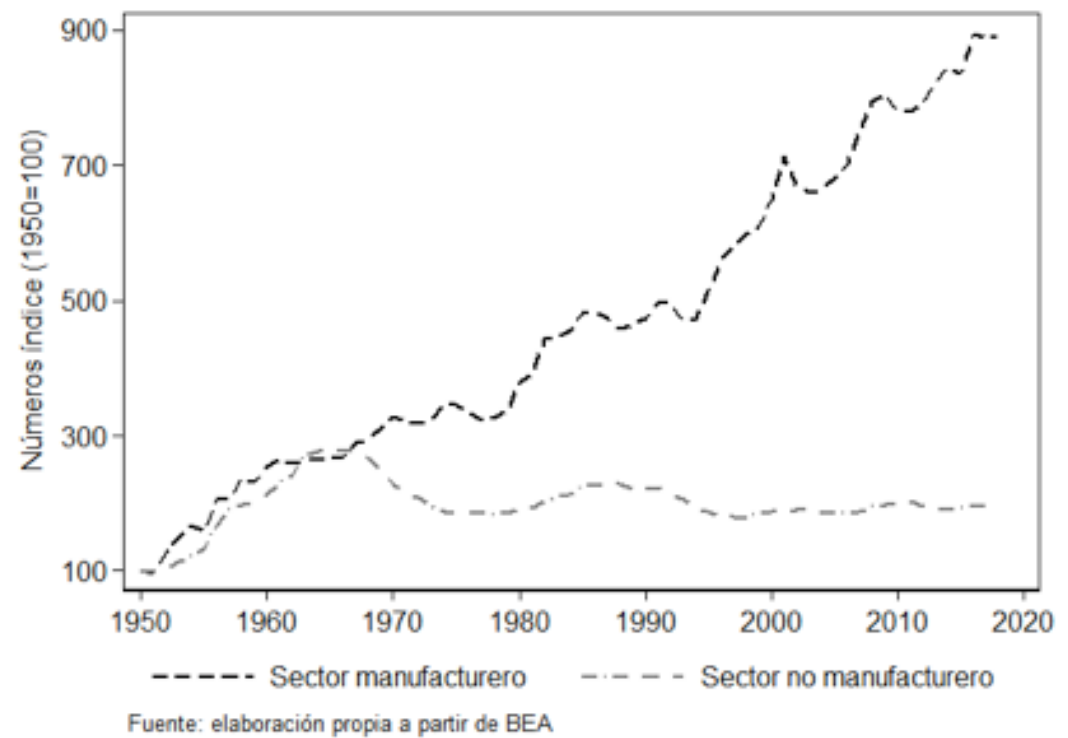

significativas y presentan el signo esperado. Asimismo, los coeficientes se mantienen estables en ambos periodos. Como evidenciaba el Grăfico 2, en el periodo 1970-2018 se produce una fuerte desaceleración en el crecimiento del output en ambos sectores. Dado que la desaceleración es más fuerte en la manufactura, esto da lugar a un deterioro de su diferencial en el crecimiento del output. De acuerdo con nuestros resultados, este deterioro en el diferencial no se explica por la contribución de los elementos de la demanda interna. En la medida en que el consumo final en bienes manufactureros y la inversión en bienes de equipo resisten en mayor grado la desaceleración que el consumo final de productos no manufactureros y la inversiōn residencial y en estructuras, los elementos de la demanda interna en el sector manufacturero contribuyen en una magnitud notablemente más reducida (-0,5 puntos) a la desaceleraciōn del incremento del output que los elementos de la demanda interna en el sector no manufacturero (-1,2 puntos). En estas circunstancias, el sector manufacturero ha sufrido una mayor desaceleraciōn en el crecimiento de su producción debido al despegue de su penetraciōn importadora a partir de la década de los setenta (Gráfico 6), que contribuye negativamente en -1 punto. El moderado deterioro del diferencial en el crecimiento del output se explica así por la fuerte erosión en la capacidad del sector manufacturero estadounidense para responder mediante producciōn interna a su persistente demanda. 
En relación al comportamiento de la productividad del trabajo (ecuaciones (4) y (8)), ambos sectores exhiben rendimientos crecientes a escala. Mientras que la manufactura presenta un coeficiente de Verdoorn cercano al habitualmente encontrado en la literatura $(0,5)$, el sector no manufacturero exhibe un coeficiente más elevado $(0,7)$. De acuerdo con nuestros resultados, las superiores tasas de crecimiento de la productividad observadas en la manufactura no se explicarían por sus mayores rendimientos a escala, sino por la acción conjunta de dos factores: 1) el papel del crecimiento del coeficiente capital-producto, que presenta un coeficiente sustancialmente superior para el sector manufacturero y 2) el incremento exógeno que tiene lugar en el crecimiento de la productividad del sector manufacturero en 19702018. Aunque este hecho parece contradecirse con la teoría kaldoriana, la consideraciōn del incremento en el coeficiente capital-producto como exógeno con respecto al crecimiento de la demanda contribuiría a explicar por qué se ha encontrado un coeficiente de Verdoorn superior para el sector no manufacturero.

A la luz de estos resultados, la desaceleración de la productividad sufrida por el sector no manufacturero en 1970-2018 se encontraría explicada por la contribución negativa que se deriva de la ralentización en el incremento del output $(-0,9)$. Si bien el sector manufacturero sufre una contribución negativa de la misma magnitud como fruto de la menor expansión de la producciōn,

\section{GRĀFICO 6. EVOLUCIŌN DE LA PENETRACIŌN IMPORTADORA POR SECTORES}

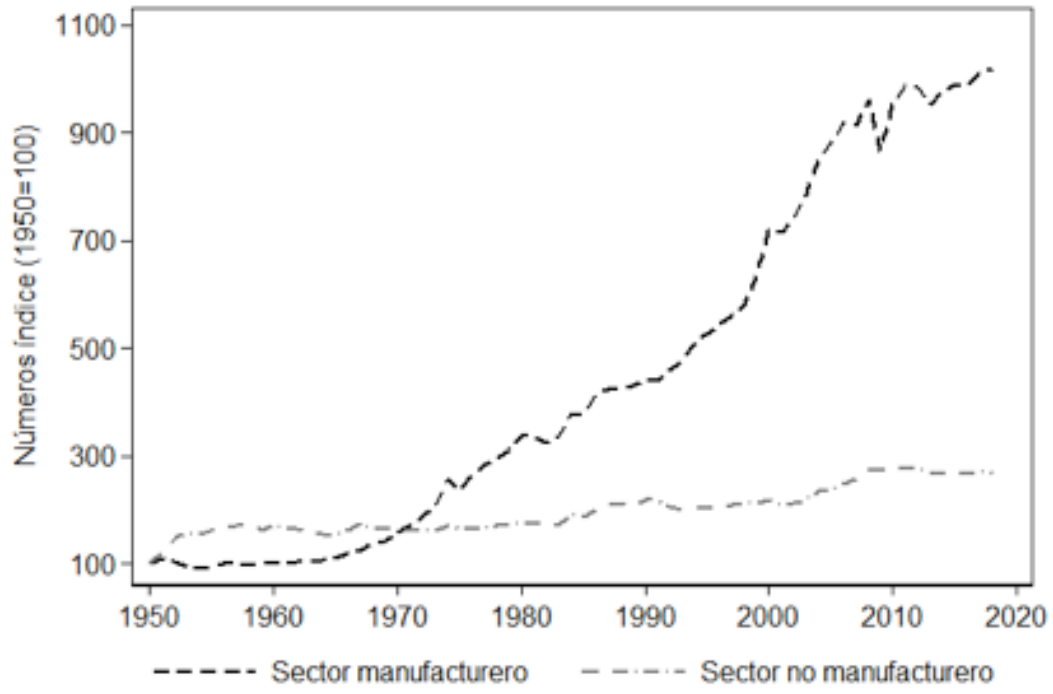

Fuente: elaboración propia a partir de BEA 
el incremento exógeno experimentado en el crecimiento de su productividad (1,5 puntos) en 1970-2018 contrarresta dicho impacto negativo, acelerando la productividad del sector. En consecuencia, la ampliaciōn del diferencial en el crecimiento de la productividad no se explicaría por la acción de los factores que conducen a la desaceleración de la productividad en el sector no manufacturero (pues esos factores tambiēn impactan de manera similar sobre la productividad de la manufactura), sino por el incremento exógeno de la productividad en el sector manufacturero.

Sobre la base de la evidencia que hemos aportado en cada una de las ecuaciones de nuestro modelo, es posible concluir que la desaceleración de la productividad en el sector no manufacturero y en el conjunto de la economía en 1970-2018 está vinculada a una ralentización en el incremento del consumo final de productos no manufactureros auspiciada por el auge de la ratio de la deuda de los hogares sobre el PIB y una distribuciōn del ingreso más favorable a los beneficios. Asī, la acciōn de estas dos variables da lugar a un proceso de desaceleración de la causación acumulativa por el cual la ralentización en el crecimiento del consumo final del sector no manufacturero desacelera el crecimiento del PIB y de la productividad, debilitando la acción del efecto acelerador en la demanda de inversiōn residencial, en estructuras y en bienes de equipo, así como también el crecimiento de los distintos componentes del ingreso por hora, lo que conduce a una ulterior desaceleraciōn del consumo final en ambos sectores.

Con todo, los factores que conducen a la ralentización de la causación acumulativa y de la productividad agregada no parecen estar interrelacionados con la aceleración del proceso de desindustrializaciōn. La aceleración del retroceso relativo de la manufactura sobre el empleo se encontraría vinculada con la acción de dos factores exógenos que no permiten explicar la desaceleración de la productividad agregada. El primero de estos factores es el incremento exógeno de la productividad en el sector manufacturero en 1970-2018, que impulsa con fuerza el diferencial en el crecimiento de la productividad. El segundo de estos factores es el despegue de la penetración importadora en la manufactura. Como hemos visto, aunque en el sector manufacturero el auge del esfuerzo innovador y el incremento de la cuota de beneficios contrarrestan el impacto negativo sobre la demanda final interna del sector que se deriva del debilitamiento de la causación acumulativa, el incremento de la penetraciōn importadora provoca que este sector sufra un deterioro en el crecimiento de su producción moderadamente superior al del sector no manufacturero. En consecuencia, la acción conjunta de estos dos factores conduce a una aceleración tanto del proceso de desindustrialización como de la productividad del sector manufacturero. De esta manera, la aceleración del proceso de desindustrializaciōn permitiría contrarrestar levemente la ralentización de la productividad agregada auspiciada por el auge de la ratio de la deuda de los hogares sobre el PIB y una distribución del ingreso más favorable a los beneficios. 


\section{ConClusiones}

En este trabajo se ha analizado la interrelación existente entre dos procesos sufridos por la economía estadounidense tras el final de la Edad de Oro: la aceleración de su desindustrialización y la ralentización en el crecimiento de su productividad del trabajo. Para ello, hemos estimado un modelo de ocho ecuaciones en el que se ha incorporado el cambio estructural en un marco de causaciōn acumulativa.

Como evidencian nuestros resultados, la desaceleraciōn de la productividad agregada se vincula con un shock negativo sobre la demanda de consumo final del sector no manufacturero auspiciado por una distribución del ingreso más favorable a los beneficios y por el auge de la ratio de la deuda de los hogares sobre el PIB. Así, la acciōn de estos dos factores da lugar a un proceso de desaceleraciōn de la causaciōn acumulativa por el cual la ralentización en el crecimiento del consumo final del sector no manufacturero desacelera el crecimiento del PIB y de la productividad.

Por el contrario, la aceleración del proceso de desindustrialización se vincularía con la acciōn de dos factores exógenos que no permiten explicar la desaceleración de la productividad agregada. El primero de estos factores es el incremento exógeno de la productividad en el sector manufacturero, vinculado fundamentalmente a la revolución tecnológica auspiciada por el auge de la electrónica. A pesar de que la desaceleración de la causación acumulativa despliega un impacto negativo similar sobre el crecimiento de la productividad de ambos sectores, en el sector manufacturero este incremento exógeno de la productividad amplía con fuerza el diferencial entre sectores, acelerando el proceso de desindustrialización. El segundo de estos factores es el despegue de la penetraciōn importadora en la manufactura. Si bien la demanda final interna del sector manufacturero sufre una desaceleraciōn más moderada que la del sector no manufacturero, el incremento de la penetración importadora conduce al deterioro del diferencial en el crecimiento del output, acelerando el proceso de desindustrializaciōn. En consecuencia, la acciōn conjunta de estos factores de desindustrializaciōn impulsa el crecimiento de la productividad del sector manufacturero y permite contrarrestar de manera leve el impacto negativo que se deriva de la desaceleración de la causación acumulativa sobre el crecimiento de la productividad agregada.

Nuestro marco de causación acumulativa con cambio estructural nos ha permitido identificar este efecto contrarrestante del proceso de desindustrialización sobre el crecimiento de la productividad, que solo puede ser identificado si el cambio estructural se endogeniza con respecto a los factores que conducen al crecimiento de la productividad. Con todo, como hemos visto, los factores que dirigen el crecimiento de la productividad en el conjunto de la economía no determinan necesariamente el proceso de cambio estructural, de manera que la desaceleración de la productividad agregada no se encuentra estrechamente relacionada con la aceleración del proceso de desindustrialización. 


\section{REFERENCIAS}

Álvarez-Cuadrado, F., Long, N.V., and Poschke, M. (2017). Capital-Labor Substitution, Structural Change, and Growth. Theoretical Economics, 12, 1229-1266.

Araujo, R., and Trigg, A. (2015). A Neo-Kaldorian Approach to Structural Economic Dynamics. Structural Change and Economic Dynamics, 33, 25-36.

Baccaro, L., and Pontusson, J. (2016). Rethinking Comparative Political Economy: The Growth Model Perspective. Politics \& Society, 44 (2), 175-207.

Basu, D., and Foley, D. (2013). Dynamics of Output and Employment in the US Economy. Cambridge Journal of Economics, 37 (5), 1077-1106.

Baumol, W. (1967). Macroeconomics of Unbalanced Growth: The Anatomy of Urban Crisis. American Economic Review, 57 (3), 415-426.

Berardino, C., and Onesti, G. (2020a). Explaining Deindustrialisation from a Vertical Perspective: Industrial Linkages, Producer Services, and International Trade. Economics of Innovation and New Technology. https://doi.org/ 10.1080/10438599.2020.1763550

Berardino, C., and Onesti, G. (2020b). The Two-Way Integration Between Manufacturing and Services. The Service Industries Journal, 40 (5-6), 337-357.

Boyer, R. (1988). Formalizing Growth Regimes. In Dosi G. et al. (eds.), Technical Change and Economic Theory. Pinter Publ., London, 608-630.

Boyer, R., and Petit, P. (1981). Progrès technique, croissance et emploi: un modèle d'inspiration kaldorienne pour six industries européennes. Revue Economique, 32 (6), 1113-1153.

Carlin, W., Glyn, A., and Van Reenen, J. (2001). Export Market Performance of OECD Countries: An Empirical Examination of the Role of Cost Competitiveness. The Economic Journal, 111 (468), 128-162.

Castellaci, F., and Âlvarez, I. (2006). Innovation, Diffusion and Cumulative Causation: Changes in the Spanish Growth Regime, 1960-2001. International Review of Applied Economics, 20 (2), 223-241.

Ciriaci, D., Moncada-Paternō-Castello, P., and Voigt, P. (2016). Innovation and Job Creation: A Sustainable Relation? Eurasian Business Review, 6, 189213.

Di Meglio, G. et al. (2018). Services in Developing Economies: The Deindustrialization Debate in Perspective. Development and Change, 49 (6), 14951525.

Dixon, R., and Thirlwall, A. (1975). A Model of Regional Growth-Rate Differences on Kaldorian Lines. Oxford Economic Papers, 27, 201-214.

Fabricant, S. (1942). Employment in Manufacturing: 1899-1937. NBER, New York.

Falk, M., and Hagsten, E. (2018). Employment Impacts of Market Novelty Sales: Evidence for Nine European Countries. Eurasian Business Review, 8, 119-137. 
Gallouj, F., and Savona, M. (2009). Innovation in Services: A Review of the Debate and a Research Agenda. Journal of Evolutionary Economics, 19 (2), 149-172.

Gualerzi, D. (2010). The Coming of Age of Information Technologies and the Path of Transformational Growth: A Long Run Perspective on the 2000s Recession. Routledge, London.

Gualerzi, D. (2012). Towards a Theory of the Consumption-Growth Relationship. Review of Political Economy, 24 (1), 33-50.

Hidalgo, C. et al. (2007). The Product Space Conditions the Development of Nations. Science, 317, 482-487.

Hidalgo, C., and Hausmann, R. (2009). The Building Blocks of Economic Complexity. Proceedings of the National Academy of Sciences of the United States of America, 106 (26), 10570-10575.

Jorgenson, D., Ho, M., and Samuels, J. (2012). A Prototype Industry-Level Production Account for the United States, 1947-2010. Second World KLEMS Conference, Harvard University, August 9.

Kaldor, N. (1966). Causes of the Slow Rate of Economic Growth of the United Kingdom. An Inaugural Lecture. Cambridge University Press, Cambridge.

Kaldor, N. (1968). Productivity and Growth in Manufacturing Industry: A Reply. Economica, 35 (140), 385-391.

Kaldor, N. (1970). The Case for Regional Policies. Scottish Journal of Political Economy, 17, 337-348.

Kaldor, N. (1975). Economic Growth and the Verdoorn Law. A Comment on Mr Rowthorn's Article. The Economic Journal, 85 (340), 891-896.

León-Ledesma, M. (2002). Accumulation, Innovation and Catching-Up: An Extended Cumulative Growth Model. Cambridge Journal of Economics, 26 (2), 201-216.

Magacho, G., and McCombie, J. (2017). Verdoorn's Law and Productivity Dynamics: An Empirical Investigation into the Demand and Supply Approaches. Journal of Post Keynesian Economics, 40 (4), 600-621.

McCombie, J. (1982). Economic Growth, Kaldor's Laws and the Static-Dynamic Verdoorn Law Paradox. Applied Economics, 14, 279-94.

McCombie, J., and Spreafico, M. (2016). Kaldor's 'Technical Progress Function' and Verdoorn's Law Revisited. Cambridge Journal of Economics, 40 (4), 1117-1136.

Metcalfe, J., Foster, J., and Ramlogan, R. (2006). Adaptive Economic Growth. Cambridge Journal of Economics, 2006, 30, 7-32.

Naastepad, C., and Storm, S. (2006). OECD Demand Regimes (1960-2000). Journal of Post Keynesian Economics, 29 (2), 211-246.

Ngai, L., and Pissarides, C. (2007). Structural Change in a Multi-Sector Model of Growth. American Economic Review, 97, 429-443.

Pasinetti, L. (1981). Structural Change and Economic Growth: A Theoretical Essay of the Dynamics of the Wealth of Nations. Cambridge University Press, Cambridge. 
Pasinetti, L. (1993). Structural Economic Dynamics: A Theory of the Economic Consequences of Human Learning. Cambridge University Press, Cambridge. Pieper, U. (2003). Sectoral Regularities of Productivity Growth in Developing Countries -A Kaldorian Interpretation. Cambridge Journal of Economics, 27, 831-850.

Pini, P. (1996). An Integrated Model of Cumulative Causation: Empirical Evidence for Nine OECD Countries, 1960-1990. Labour, 10 (1), 93-150.

Rodrik, D. (2013). Unconditional Convergence in Manufacturing. Quaterly Journal of Economics, 128 (1), 165-204.

Romero, J., and Britto, G. (2017). Increasing Returns to Scale, Technological Catch-Up and Research Intensity: Endogenising the Verdoorn Coefficient. Cambridge Journal of Economics, 41, 391-412.

Romero, J., and McCombie, J. (2016). Differences in Increasing Returns Between Technological Sectors: A Panel Data Investigation Using the EU KLEMS Database. Journal of Economic Studies, 43 (5), 863-878.

Setterfield, M. (2019). Export-Led Growth and Cumulative Causation. In Blecker, R., and Setterfield, M. (eds.), Heterodox Macroeconomics. Models of Demand, Distribution and Growth, Edward Elgar Publishing, 376-424.

Stockhammer, E., and Wildauer, R. (2016). Debt-Driven Growth? Wealth, Distribution and Demand in OECD Countries. Cambridge Journal of EconomiCs, 40 (6), 1609-1634.

Szirmai, A. (2012). Industrialisation as an Engine of Growth in Developing Countries. Structural Change and Economic Dynamics, 23, 406-420.

Targetti, F., and Foti, A. (1997). Growth and Productivity: A Model of Cumulative Growth and Catching Up. Cambridge Journal of Economics, 21, 27-43.

Vivarelli, M. (1995). The Economics of Technology and Employment: Theory and Empirical Evidence. Edward Elgar, Aldershot.

Young, A. (1928). Increasing Returns and Economic Progress. Economic Journal, 38, 527-542. 
